\title{
Biosynthetic studies on taxol
}

\author{
P.E. Fleming, H.G. Floss, M. Haertel, A.R. Knaggs, A. Lansing, U. Mocek and K.D. \\ Walker \\ Department of Chemistry BG-10, University of Washington, Seattle, Washington 98195 , \\ USA
}

\begin{abstract}
The biosynthesis of the plant antitumor agent, taxol, was studied by feeding radioactive or stable isotope-labeled precursors to cut stems or to inner bark tissue of Taxus brevifolia. The labeled taxol was purified to radiochemical purity and subjected to chemical degradation or was analyzed by electrospray tandem mass spectrometry. It was demonstrated that in the plant taxol is synthesized from baccatin-III, containing the fully functionalized diterpene moiety, and a precursor of the phenylpropanoid side chain. The latter arises from phenylalanine not via cinnamic acid, but via $B$-phenylalanine and phenylisoserine. Benzoylation of the side chain occurs only after its attachment to the diterpene moiety. The benzoate moiety is also formed from phenylalanine via $B$-phenylalanine and phenylisoserine, not via cinnamic acid.
\end{abstract}

Due to its unique mode of action and promising early clinical results, taxol (1) commands considerable interest as a new plant anticancer agent (2). The complexity of its structure presents a considerable challenge to synthetic organic chemistry and raises the question how the plant assembles this formidable molecule (3-5). We have studied this latter issue by feeding experiments with potential precursors labeled strategically with radioactive or stable isotopes (6).

Our studies focused initially on the origin of the phenylpropanoid side chain and its mode of attachment to the diterpene moiety. Feeding experiments with radiolabeled precursors were carried out with cut twigs of Taxus brevifolia to which the radioactive material was administered through the cut stem in a small volume of water. Extensive purification of the resulting taxol, first by repeated HPLC and then by co-crystallization with non-labeled carrier material was found necessary to achieve constant specific radioactivity or, in other cases, to remove traces of radioactive impurities. Under these conditions incorporation of $[7-14 \mathrm{C}]$ benzoic acid, as its $\mathrm{N}$-acetylcysteamine thioester $(0.09 \%)$, and $\left[13-{ }^{3} \mathrm{H}\right]$ baccatin-III $(0.12 \%)$ was obtained. Degradation of the radioactive taxol from the benzoate feeding experiment showed that $88 \%$ of the radioactivity was recovered in the side chain fragment and only $11 \%$ in the baccatin-III, suggesting that under the conditions of the experiment relatively little of the diterpene moiety was synthesized de novo. Upon degradation of the taxol from the baccatin-III feeding experiments, all the radioactivity was recovered in the baccatin-III moiety, none in the side chain fragment. 
To avoid the tedious chemical degradations, we changed to feeding experiments with deuterium labeled precursors to cambial tissue of Pacific yew. ES-MS/MS analysis of the resulting taxol and cephalomannine allowed determination of the isotope distribution between the side chain and the diterpene ring system from daughter ion spectra of the isotopomers of the molecular ion; the abundance of each isotopomer was determined from parent ion scans. As summarized in Table 1, the results clearly show formation of the side chain from phenylalanine via $B$-phenylalanine and phenylisoserine, not via cinnamic acid or its epoxide. The biosynthesis thus must involve a phenylalanine aminomutase reaction. Rather unexpectedly, $B$-phenylalanine and phenylisoserine pentadeuterated in the benzene ring gave not only pentadeuterated taxol but also molecules containing 10 atoms of deuterium. This together with the lack of incorporation of deuterium from cinnamic acid indicates that benzoic acid in this plant may be formed by a different pathway, involving $B$-phenylalanine and phenylisoserine, rather than the widely accepted one via B-oxidation of cinnamoyl-CoA (7).

TABLE 1. Incorporation of Deuterated Precursors into Taxol and Cephalomannine

\begin{tabular}{|c|c|c|c|c|}
\hline Precursor & $\underline{\text { Taxol }}$ & $\underline{\text { Side Chain }}^{\mathrm{a}}$ & Cephalomannine & Side Chain $^{\mathrm{a}}$ \\
\hline \multirow[t]{2}{*}{ [Benzoyl- $\left.{ }^{2} \mathrm{H}_{5}\right]$ Side Chain } & $\mathbf{M}$ & $\mathrm{P}_{1}$ & M & $\mathrm{P}_{2}$ \\
\hline & $\mathrm{M}+5(1.7 \%)^{\mathrm{b}}$ & $\mathrm{P}_{1}+5$ & \multicolumn{2}{|c|}{ (no $M+5$ or $P_{2}+5$ signals) } \\
\hline \multirow[t]{3}{*}{ [ring- $\left.{ }^{2} \mathrm{H}_{5}\right] \alpha$-Phenylalanine } & $\mathbf{M}$ & $P_{1}$ & $\mathbf{M}$ & $\mathrm{P}_{2}$ \\
\hline & $M+5(0.9 \%)^{b}$ & $P_{1}+5$ & $M+5$ & $\mathrm{P}_{2}+5$ \\
\hline & & & \multicolumn{2}{|l|}{ (weak) } \\
\hline \multirow[t]{3}{*}{ [ring- $\left.{ }^{2} \mathrm{H}_{5}\right] \beta$-Phenylalanine } & $\mathbf{M}$ & $P_{1}$ & $\mathbf{M}$ & $\mathrm{P}_{2}$ \\
\hline & $M+5(2.8 \%)^{b}$ & $P_{1}+5$ & \multirow[t]{2}{*}{$M+5$} & \multirow[t]{2}{*}{$\mathrm{P}_{2}+5$} \\
\hline & $\mathrm{M}+10(2.6 \%)^{\mathrm{b}}$ & $P_{1}+10$ & & \\
\hline \multirow[t]{3}{*}{ [ring- ${ }^{2} \mathrm{H}_{5}$ ]Phenylisoserine } & $\mathbf{M}$ & $P_{1}$ & $\mathbf{M}$ & $\mathrm{P}_{2}$ \\
\hline & $M+5(1.0 \%)^{b}$ & $\mathrm{P}_{1}+5$ & \multirow[t]{2}{*}{$\mathrm{M}+5$} & \multirow[t]{2}{*}{$\mathrm{P}_{2}+5$} \\
\hline & $M+10(0.9 \%)^{b}$ & $P_{1}+10$ & & \\
\hline \multirow[t]{2}{*}{ [ring- ${ }^{2} \mathrm{H}_{5}$ ]Cinnamic Acid } & $\mathbf{M}$ & $\mathrm{P}_{1}$ & $\mathbf{M}$ & $\mathrm{P}_{2}$ \\
\hline & \multicolumn{2}{|c|}{ (no $\mathrm{M}+5$ or $\mathrm{P}_{1}+5$ signals) } & \multicolumn{2}{|c|}{ (no $M+5$ or $P_{2}+5$ signals) } \\
\hline [ring- ${ }^{2} \mathrm{H}_{5}$ ]Cinnamic Acid & M & $\mathrm{P}_{1}$ & M & $\mathrm{P}_{2}$ \\
\hline Epoxide & \multicolumn{2}{|c|}{ (no $M+5$ or $P_{1}+5$ signals) } & \multicolumn{2}{|c|}{ (no $M+5$ or $P_{2}+5$ signals) } \\
\hline [10-Acetyl, $\left.13-2 \mathrm{H}_{4}\right]-$ & $\mathbf{M}$ & $P_{1}$ & M & $\mathrm{P}_{2}$ \\
\hline Baccatin-III & $\mathrm{M}+4(1 \%)^{\mathrm{b}}$ & no $P_{1}+4$ & \multicolumn{2}{|c|}{ no $M+4$ detected } \\
\hline [ring- $\left.{ }^{2} \mathrm{H}_{10}\right] \mathrm{N}-$ Benzoyl- & $\mathbf{M}$ & $\mathrm{P}_{1}$ & & \\
\hline phenylisoserine & $\mathrm{M}+5(1.8 \%)^{\mathrm{b}}$ & $\mathrm{P}_{1}+5$ & \multicolumn{2}{|c|}{ not analyzed } \\
\hline \multicolumn{5}{|c|}{ (no $M+10$ or $P_{1}+10$ signals) } \\
\hline [side chain- ${ }^{2} \mathrm{H}_{5}, 10$-acety]- & $\mathrm{M}$ & $P_{1}$ & $\mathbf{M}$ & \\
\hline \multirow[t]{3}{*}{$\left.{ }^{2} \mathrm{H}_{3}\right] \mathrm{N}$-Debenzoyltaxol } & $M+3 \quad(<1 \%)$ & & \multicolumn{2}{|l|}{$M+3(<1 \%)$} \\
\hline & $M+5 \quad(0.8 \%)$ & & \multicolumn{2}{|l|}{$M+5(0.8 \%)$} \\
\hline & $\mathrm{M}+8 \quad(5.9 \%)^{\mathrm{b}}$ & & \multicolumn{2}{|l|}{$\mathrm{M}+8(5.0 \%)^{\mathrm{b}}$} \\
\hline
\end{tabular}

a $P_{1}, \mathrm{~m} / \mathrm{z} 286 ; P_{2}, \mathrm{~m} / \mathrm{z} 264 ;$ no significant incorporation was observed into the ring fragment $\mathrm{m} / \mathrm{z} 569$. bEnrichments from different precursors are not necessarily comparable since the experiment were carried out at different times and we have noted substantial seasonal differences in incorporation rates. 
Although incorporation of the complete side chain, labeled in the benzoate moiety, into the side chain moiety of taxol was observed, a double labeling experiment in which both aromatic rings of the intact side chain were pentadeuterated, gave very little if any taxol containing 10 atoms of deuterium. Since a control experiment with radiolabeled side chain indicated that hydrolysis of the benzamide linkage is not a very rapid process, this result can only be interpreted to mean that it is not the intact side chain that is attached to baccatin-III. This was confirmed in an experiment with double-labeled Ndebenzoyltaxol, carrying 5 atoms of deuterium in the side chain and 3 in the 10-acetyl moiety. The abundant appearance of molecules of taxol as well as cephalomannine containing 8 atoms of deuterium is clear evidence that acylation of the nitrogen occurs only after linkage of the phenylpropanoid moiety to the diterpene (8). The synthesis of 13-B-phenylalanyl-baccatin-III is underway to distinguish whether attachment of the side chain occurs before or after hydroxylation.

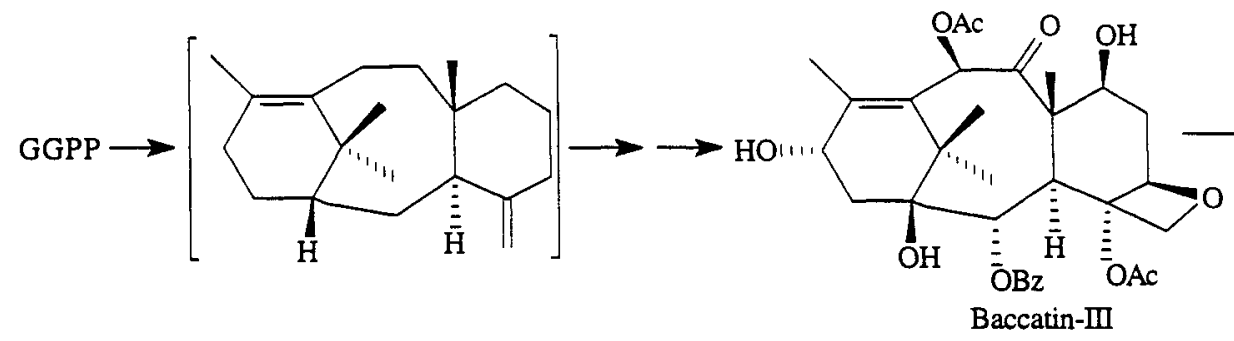

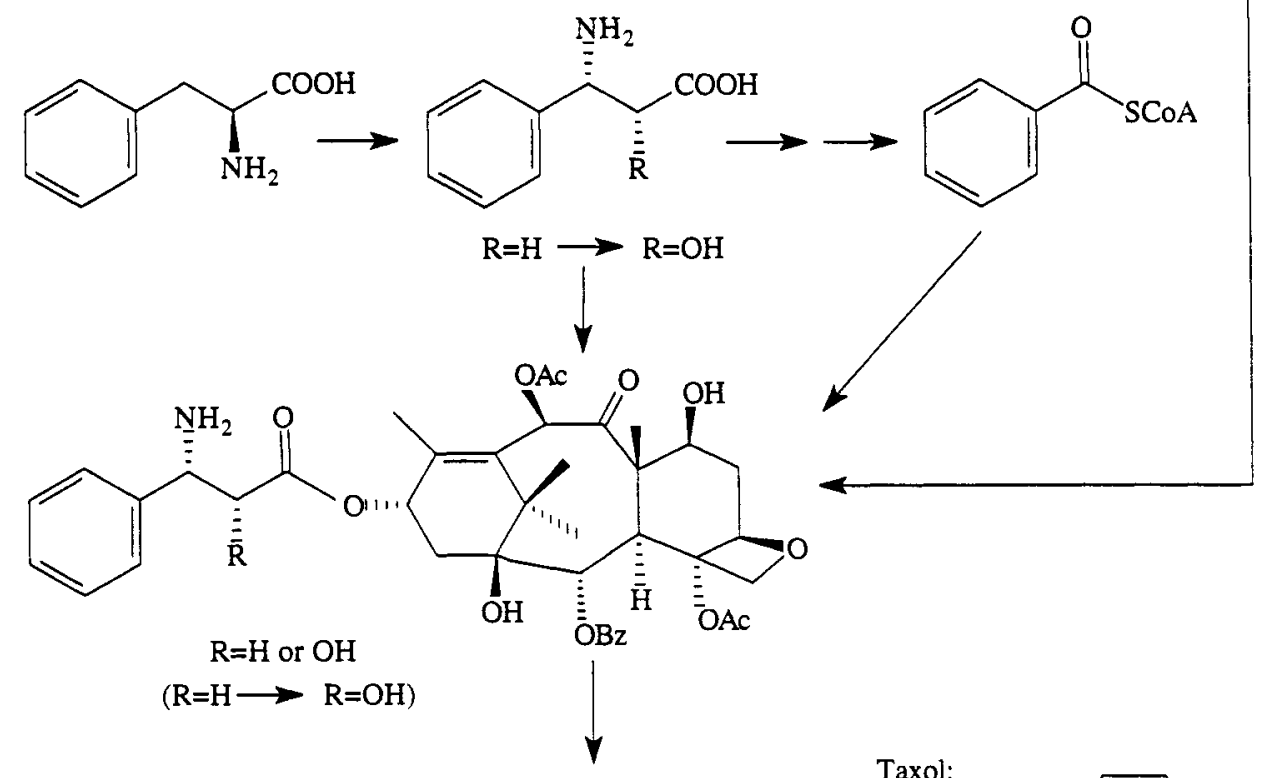

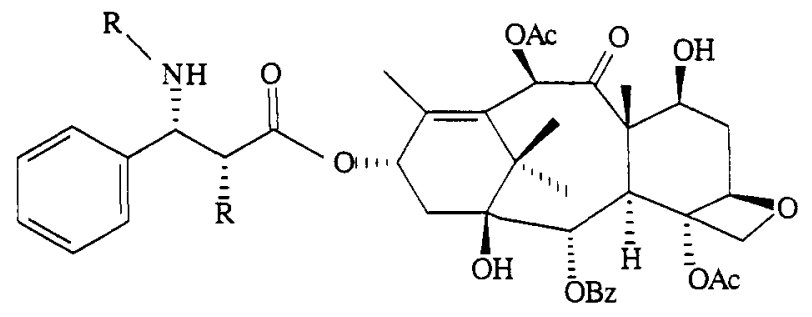

Taxol:<smiles>[R]C(=O)c1ccccc1</smiles>

(Cephalomannine:<smiles>[R]C(=O)C(C)=C(C)C</smiles>

Fig. 1. The late steps in the biosynthesis of taxol. 
Based on the above results the biosynthesis of taxol can be formulated as shown in Figure 1. The mode of formation of the diterpene moiety is at present a matter of speculation. Based on general biochemical knowledge one predicts the acyclic precursor to be geranylgeranyl pyrophosphate, which would be predicted to undergo a stepwise or concerted cyclization to a hypothetical hydrocarbon precursor, 4(20),11-taxadiene. Its subsequent functionalization to baccatin-III requires a series of hydroxylations and acylations and the construction of the oxetane ring, probably via a 5-hydroxy4,20-epoxide. The elucidation of the detailed sequence of these reactions will be the subject of further studies.

Acknowledgments. This work was supported by the American Cancer Society, by Panlabs, Inc., by a postdoctoral fellowship to A. L. from the Alexander v. Humboldt Foundation, and by predoctoral fellowships to P.E.F. (NIH, NRSA \# GM 08437) and to K.D.W. (NSF). We are grateful to these sponsors for their support.

\section{REFERENCES}

1. M.C. Wani et al. J. Amer. Chem. Soc. 93, 2325 (1971).

2. Cf.: D.G.I. Kingston et al. Prog. Chem. Org. Nat. Prod. 61, 1 (1993).

3. M.J. Begley et al. Tetrahedron 46, 4907 (1990).

4. N.R. Lewis and R. Croteau. Taxol Biosynthesis, Second National Cancer Institute Workshop on Taxol and Taxus," Alexandria, VA, Sept. 1992.

5. F. Guéritte-Voegelein et al. J. Nat. Prod. 50, 9 (1987).

$6 \quad$ P.E. Fleming et al. J. Amer. Chem. Soc. 115, 805 (1993).

7. J.A. Bjorklund and E. Leete. Phytochem. 31, 3883 (1992); and references therein.

8. P. E. Fleming et al. Manuscript in preparation. 